\title{
Contribuição da Psicodinâmica do Trabalho para o debate: "o mundo contemporâneo do trabalho e a saúde mental do trabalhador"
}

\author{
Contribution of Psychodinamics of Work to the debate "the \\ contemporary world of work and worker's mental health"
}

${ }^{1}$ Docente do Departamento de Engenharia de Produção (DEENP) do Instituto de Ciências Exatas e Aplicadas (ICEA) da Universidade Federal de Ouro Preto (UFOP) - Campus João Monlevade-MG.

Contato:

Universidade Federal de Ouro Preto (UFOP), Campus de João Monlevade Rua 37, no 115 - Bairro Loanda João Monlevade-MG CEP: 35930-970

E-mail:

gilbertcb@uol.com.br

\section{Resumo}

O principal propósito deste artigo é ampliar o cenário teórico atual da Saúde Mental e Trabalho. Por isso, o texto se baseia, também, nas nossas próprias contribuições para esta área nos últimos dez anos de pesquisas empíricas e teóricas, em contextos de produção industrial e de serviços. Propõe-se discutir, por meio de algumas incursões no campo da saúde mental e trabalho, as repercussões psíquicas geradas pelo trabalho contemporâneo. O artigo debate, também, aspectos teóricos e práticos das relações entre organizações do trabalho contemporâneas e a subjetividade, de acordo com a Psicodinâmica do Trabalho, em seus fundamentos teóricos na psicanálise e na tradição compreensiva das ciências hermenêuticas. Utilizamos as atuais contribuições da clínica do trabalho dejouriana para a compreensão das relações entre saúde mental e trabalho. Há, também, referências à Psicodinâmica do Trabalho aplicada em organizações contemporâneas (indústria e serviços) baseadas na proposta teórico-metodológica de Dejours.

Palavras-chave: saúde mental e trabalho; subjetividade; Psicodinâmica do Trabalho.

\begin{abstract}
The main purpose of this paper is to amplify the current theoretical scenery of Mental Health and Work area. Therefore, the text is also based on our own contributions to this area in the last ten years of empirical and theoretical research within the context of industrial production and services. The study discusses the psychological effects of contemporary work, by entering into the Work and Mental Health field. It also discusses the theoretical and practical aspects of the relationships between contemporary work organizations and subjectivity, according to Psychodynamics of Work, based on it's theory of Psychoanalysis and on the comprehensive tradition of hermeneutics sciences. The current contributions of the Dejourian Clinic of Work was used to understand the relationship between mental health and work. There are also references to Psychodynamics of Work applied in contemporary organizations (industry and services) based on Dejour's theoretic-methodological proposal.
\end{abstract}

Keywords: mental health and work; subjectivity; psychodynamics of work. 


\section{Introdução}

Este texto sintetiza algumas de nossas contribuições teóricas, nos últimos anos, para o campo geralmente interdisciplinar e transdisciplinar da "Saúde Mental e Trabalho" que podem ser úteis para o debate: "o mundo contemporâneo do trabalho e a saúde mental do trabalhador". Utilizamos aqui os resultados de nossos estudos empíricos, nos setores industrial e de serviços, sem uma preocupação em relatar os dados quantitativos e as metodologias, visto que isso já foi detalhado em diversos trabalhos anteriores e, principalmente, porque, no presente texto, o essencial e o mais importante foi priorizar e ressaltar as contribuições teóricas destes estudos para o debate ora em questão. Escolhemos tratar de dois casos específicos de produção: um, de serviços de teleatendimento. O outro, da indústria de processos contínuos cujas peculiaridades no tocante à organização do trabalho são amplamente discutidas na literatura (MORAES NETO, 1989). Os dois casos aqui apresentados, de produção de serviços e de produção industrial, são ícones que talvez possam ser extrapolados para a compreensão de diversas outras situações de trabalho no que tange à relação trabalho-saúde.

Nossas contribuições para o presente debate vão ao encontro dos passos mais recentes da evolução da Psicodinâmica do Trabalho, dentre eles, a ressonância que a abordagem dejouriana encontrou com o caminho trilhado pela tradição compreensiva das ciências humanas (LANCMAN; UCHIDA, 2003). Christophe Dejours incorpora as contribuições desta questão hermenêutica, conforme já apontamos também em outros trabalhos anteriores. Isso trouxe severas implicações teóricas e metodológicas para o campo da Psicologia do Trabalho, contribuindo para o seu distanciamento de uma abordagem psicologizante ou muito abstrata, ainda que no interior de uma psicologia aplicada (DEJOURS, 1996), fragmentada pelas distinções entre ciências da natureza e ciências do espírito.

Por ora, destacaremos como noções centrais da Psicodinâmica do Trabalho, com base em diversos estudos nos setores industrial e de serviços: 1) reconhecimento; 2) identidade; 3) compromisso entre sofrimento e de fesa; 4) sublimação; 5) racionalidade pática (pathique); 6) alienação social. Essas noções permitem compreender (dentro de uma tradição compreensiva e de construção de sentido pelos atores da organização do trabalho) as relações entre saúde mental e trabalho contemporâneo. Ressaltaremos, neste texto, os problemas que o trabalho moderno impõe à formação da identidade, apoiados tanto em pesquisas teóricas quanto empíricas:

Um dos pontos mais destacados na Psicodinâmica do Trabalho é a importância do trabalho na formação da identidade. A constituição da identidade é aqui entendida como processo que se desenvolve ao longo de toda a vida do sujeito, e que está vinculada à noção de alteridade. Este processo deixa sempre em aberto uma lacuna, que nunca é preenchida. É a partir do "olhar do outro" que nos constituímos como sujeitos; é justamente na relação com o outro que nos reconhecemos em um processo de busca de semelhanças e de diferenças; são as relações cotidianas que permitem a construção da identidade individual e social, a partir de trocas materiais e afetivas, fazendo com que o sujeito, ao longo de toda a sua vida, constitua sua singularidade em meio às diferenças. Na vida adulta, o espaço do trabalho será o palco privilegiado dessas trocas. Ele aparece como o mediador central da construção, do desenvolvimento, da complementação da identidade e da constituição da vida psíquica. (LANCMAN, 2008, p. 34)

Acompanhando a evolução epistemológica deste nosso campo de atuação, verificamos que algo de inovador ocorre na compreensão das implicações do trabalho sobre a saúde mental. Face às modificações do próprio trabalho, em especial com o crescimento econômico do setor de serviços e com o amplo emprego das tecnologias microeletrônicas no cenário produtivo contemporâneo, ninguém ousaria negar que o trabalho se torna menos material, menos concreto (GALVÃO; SILVA; COCCO, 2003) cedendo terreno à proeminência dos componentes cognitivos, psíquicos e afetivos da carga de trabalho.

Patologia é o termo comumente usado, na literatura de Psicologia do Trabalho, para designar "descompensação psicopatológica, ou seja, uma ruptura do equilíbrio psíquico que se manifesta pela eclosão de uma doença mental” (DEJOURS, 2006, p. 35). Ao longo deste texto, quando usarmos o termo patologia, estaremos nos referindo a estas descompensações..., como também é comumente feito por Dejours em seus textos. Cabe ressaltar aqui que uma grande contribuição da Psicodinâmica do Trabalho (epistemológica e teórico-metodológica) para a Psicologia do Trabalho (e para o campo da saúde mental e trabalho) foi mostrar e demonstrar que, "se o sofrimento não se faz acompanhar de descompensação psicopatológica, é porque contra ele o sujeito emprega defesas que lhe permitem controlá-lo" (DEJOURS, 2006, p. 35). A questão da normalidade torna-se, assim, um foco de interesse na abordagem dejouriana, conforme exploraremos mais adiante.

Ou seja, defendemos a tese, apoiados na Psicodinâmica do Trabalho, de que o que temos, então, de inovador, do ponto de vista epistemológico no campo da saúde mental e trabalho, é que o conhecimento das novas patologias do mundo contemporâneo do trabalho (ou, quiçá, da normalidade...) tem se deslocado, profundamente, rumo: 1) à imaterialidade do trabalho predominantemente cognitivo e subjetivo (novas tecnologias da informática, automação microeletrônica, produção intangível dos serviços) em contraponto à antiga materialidade concreta dos processos de produção; 2) ao sujeito em contrapartida ao objeto; 3) à subjetividade das condutas e da ação em contraponto à objetividade do comportamento visível; 4) à experiência vivida, i.e., a vivência psíquica do sujeito no trabalho em contrapartida às experiências concretas experimentadas num dado posto de trabalho (temperatura, ruído, agentes químicos, vibrações, iluminação etc.); 5) à normalidade (sofrimento e defesas) em contraponto à patologia. 


\section{Contribuições da Psicodinâmica do Tra- balho para a compreensão do problema em pauta: tese proposta}

O campo da Psicopatologia do Trabalho tem seus primórdios arraigados em uma fértil materialidade, em uma coerente concretude das condições de trabalho, haja vista os trabalhos de Le Guillant, Begoin, Sivadon. A Psicologia do Trabalho, na França, também emergiu de trabalhos que se amarravam, de uma forma ou de outra, nos aspectos concretos das condições de trabalho, como atestam o movimento higienista de 1802 e a criação da liga de higiene mental, e os trabalhos de Edouard Toulouse (um dos fundadores da Psiquiatria Social), Armand Imbert, Josepha Joteyko e Jean-Maurice Lahy, entre meados do século XIX e as primeiras décadas do século XX. Contribuições importantes foram auferidas pela Psicologia do Trabalho, na França, pelas interações com a Ergonomia francesa. Tal contribuição da Ergonomia à Psicologia do Trabalho desponta e se consolida, em especial, com os estudos de Suzane Pacaud (por volta de 1946) e, posteriormente, com Ombredane, Faverge, Leplat, Theureau, Pavard, Catherine Teiger, Alain Wisner e François Daniellou.

Não se trata, aqui, de negar as condições concretas da atividade de trabalho e suas implicações na saúde mental. Trata-se, por ora, de apontar que algo interessante vem ocorrendo na compreensão atual sobre as patologias relacionadas ao trabalho: um deslocamento epistemológico do campo interdisciplinar "Saúde Mental e Trabalho" (e da Psicologia do Trabalho) rumo aos aspectos nem tanto concretos, nem tanto materiais do trabalho e, assim, mais próximos da vivência subjetiva dos que trabalham. Isso ficará evidenciado quando focarmos as contribuições da Psicodinâmica do Trabalho no entendimento das relações prazer-sofrimento-trabalho no contexto contemporâneo da produção de serviços, tendo como exemplo o serviço de teleatendimento, e na moderna indústria automatizada cujo exemplo paradigmático, segundo Moraes-Neto (1989), é a indústria de processo contínuo.

Parte da obra de Dejours propõe pensar a normalidade - ou o enigma da normalidade (DEJOURS, 1996, p. 198). Ele utiliza, ainda, em outro texto, a expressão "normalidade como enigma" (DEJOURS; ABDOUCHELI; JAYET, 1994, p. 127) e "normalidade enigmática” (p. 126). A normalidade é um compromisso entre sofrimento e defesa - em contraponto às patologias como abordadas na Psiquiatria clássica. Diferente desta, na Psicodinâmica do Trabalho ressalta-se a questão da centralidade do trabalho na Psicologia. Esta expressão, "centralidade do trabalho na Psicologia", usada pelo autor, significa que o trabalho não é um objeto particular entre tantos outros, mas que está colocado no centro da Psicologia, no mesmo nível que a sexualidade (DEJOURS, 1996, p. 199), ou seja, "não há neutralidade do trabalho diante da saúde mental. Mas esta dimensão pática (pathique) do trabalho é amplamente subestimada nas análises..." (DEJOURS, 2006, p. 35).
A racionalidade pática visa não ao sucesso da ação segundo o mundo social, mas à coesão e à coerência entre a ação e os objetivos do sujeito em conservar sua saúde. Certas condutas podem contrariar o que seria socialmente esperado porque estão em contradição com a racionalidade instrumental. No cerne da racionalidade pática (ou subjetiva), são absolutamente racionais porque contribuem na conservação de si, "protegendo o corpo da doença e o espírito da loucura" (DEJOURS, 1996, p. 204). A racionalidade pática liga-se aos objetivos do sujeito para a conservação de si e de seu mundo subjetivo. Esta racionalidade não tem por finalidade principal o sucesso da ação ao olhar do mundo social, mas sim, a proteção do sujeito.

No universo desta centralidade do trabalho, a Psicodinâmica do Trabalho amplia o conhecimento dos limites entre normalidade e patologias, tomando como objeto as defesas e as estratégias defensivas que, na Psicanálise convencional, não se entrelaçaram com o contexto da atividade de trabalho. As estratégias coletivas de defesa vieram preencher um espaço dantes enigmático das articulações entre o singular e o coletivo no contexto pautado pelo trabalho enquanto mediador essencial. A Psicologia do Trabalho agora tem, no trabalho, o seu operador de inteligibilidade primordial para compreensão dos processos relativos à saúde mental ou às patologias, buscando compreender, também, outros processos que se passam na imaterialidade e na quase intangibilidade das vivências psíquicas (como o sofrimento), numa normalidade enigmática.

Ora, a normalidade torna-se, então, um objeto de estudo científico. Uma evolução trazida pela Psicodinâmica do Trabalho foi colocar também a normalidade como foco de suas atenções, ampliando o escopo para além da visão (até então limitada) de que um problema de investigação deveria ser somente aquele pautado pela concretude de uma lesão ou de uma descompensação psicopatológica. No lugar dessa materialidade concreta do adoecimento, as pessoas, no mundo do trabalho contemporâneo, sofrem e suportam um sofrimento que, se não as leva ao estado de descompensação psicopatológica, é porque entram em jogo as defesas. A este jogo entre sofrimento e defesa, numa normalidade enigmática, conforme expressão do autor, Dejours (1996, p. 198-199) dá o nome de compromisso. Destaca-se, nessa evolução da Psicodinâmica do Trabalho, a adoção, também, da noção de experiência vivenciada:

\footnotetext{
Na psicodinâmica do trabalho, o sofrimento é uma experiência vivenciada, ou seja, é um estado mental que implica um movimento reflexivo da pessoa sobre seu "estar no mundo", para utilizar um conceito da fenomenologia alemã, aplicado à condição de trabalhador. (...) O conceito de sofrimento pertence à ordem do singular; o sofrimento coletivo é inconcebível, já que não existe corpo coletivo. Se, clinicamente, se observam estratégias coletivas de defesa fundadas em uma cooperação entre sujeitos, por outro lado o sofrimento permanece sempre individual e único. (DEJOURS, 1999, p. 19)
} 
Dentro mesmo da normalidade, algo de anormal ocorre: as pessoas aparentam normalidade, as pessoas que trabalham estão normais, mas, em suas vivências (ou em sua experiência vivenciada, como anteriormente explicado por Dejours), em sua experiência subjetiva mais íntima, individual, experimentam um sofrimento ligado ao trabalho, o qual merece, como as patologias, atenção e investigação por parte da Psicologia do Trabalho.

A questão da normalidade leva a Psicodinâmica do Trabalho rumo à racionalidade que desempenha um papel central entre o prazer e o sofrimento no trabalho e que possui um estatuto diferente da racionalidade instrumental. Trata-se da racionalidade pática - pathique (DEJOURS, 1996, p. 204), conforme anteriormente explicado.

No Brasil, nos anos de 1980 e 1990, o estudo das patologias do trabalho geralmente esteve centrado, de um lado, na organização do trabalho (tida como patogênica e como determinante essencial do adoecimento) e nas condições de trabalho para apontar e no outro lado, as síndromes e os adoecimentos que acometiam os trabalhadores. Entre estes dois extremos, permanecia uma lacuna na compreensão de como as mazelas da organização do trabalho se convertiam em adoecimentos na estrutura biológica ou mental do trabalhador individual. Como bom exemplo, temos, nesses anos 1980 e 1990, os estudos sobre as então denominadas LER (lesões por esforços repetitivos). Alguns destes estudos focavam brilhantemente as características patogênicas de uma dada organização do trabalho (que possuía, segundo estas pesquisas, um caráter determinante essencial dos adoecimentos). No entanto, estes estudos pecavam no estabelecimento de um nexo causal, cientificamente verificável, entre a organização do trabalho e o adoecimento individual.

Como compreender esta transição do "mal" da organização do trabalho para o corpo e a mente dos indivíduos? Por quais mecanismos de ordem psicológica a patogenia da organização do trabalho se manifesta como adoecimento de um dado indivíduo, dotado de uma singularidade irredutível ao caráter genérico dos dados estatísticos de adoecimento de uma dada população em uma dada organização do trabalho?

O problema desses estudos, anteriormente citados, sobre os problemas de saúde (em especial, a saúde mental) causados pelo trabalho, desde Le Guillant e Begoin, é o mesmo detectado por Dejours quando analisa os estudos clínicos da Psicopatologia do Trabalho, incluindo o excelente estudo de Begoin sobre a neurose das telefonistas: não foi possível, neles, detectar uma patologia mental do trabalho:

Apesar de certos resultados espetaculares - em particular a neurose das telefonistas (Begoin, 1957) -, não foi possível descrever uma patologia mental do trabalho comparável à patologia das afecções somáticas profissionais, cuja variedade e especificidade, aliás, são conhecidas. (DEJOURS, 2006, p. 35)
A solução para esta lacuna entre o coletivo e o individual pode ser equacionada, também, pela Psicodinâmica do Trabalho em sua sintonia com a tradição compreensiva das ciências hermenêuticas (DEJOURS, 1996; LANCMAN; UCHIDA, 2003). Embora hoje tenhamos, naquilo que chamamos de Clínicas do Trabalho, outras abordagens que igualmente vêm pensando esta questão, optamos por focar na Psicodinâmica do Trabalho, porque nossa experiência empírica, em trabalhos de intervenção e ação prática em diferentes organizações do trabalho, tem nos demonstrado o seu poder de transformação das mesmas em benefício dos que sofrem no trabalho.

A elucidação da lacuna, ora apontada, envolve a compreensão, nos cenários do trabalho contemporâneo, de termos essenciais à Psicodinâmica do Trabalho anteriormente citados.

A Psicodinâmica do Trabalho se concentra na coletividade do trabalho (numa dada organização do trabalho) e não apenas em indivíduos isolados. Embora não faça recomendações terapêuticas individuais, mas proponha modificações reais na organização do trabalho, que atinge todo um coletivo de trabalhadores, ela não descarta as vivências singulares, as experiências individuais, como o sofrimento (DEJOURS; ABDOUCHELI; JAYET, 1994). Os seus conceitos essenciais, fundados na Psicanálise, na Hermenêutica e na Teoria da Ação (LANCMAN; UCHIDA, 2003), permitem compreender o espaço entre o que está dado na dimensão coletiva (a patogenia de uma dada organização do trabalho, como na que predomina o trabalho parcelado, repetitivo, monótono) e as suas manifestações na totalidade biopsíquica do indivíduo - não apenas a sua "normalidade sofrente” (DEJOURS, 2006, p. 36), mas também as patologias ou as descompensações psicopatológicas.

Para a saúde mental, faz-se necessário, ainda, a "psicodinâmica do reconhecimento" (DEJOURS, 2006, p. 34), ou seja, o reconhecimento, pelo outro, do esforço do ego para suprir, no real do trabalho, por meio da subjetividade e da atividade subjetivante (i.e., inteligência astuciosa, inteligência da prática - métis, e a sabedoria da prática - phronésis (DEJOURS, 1997, p. 43-48), a lacuna entre a organização do trabalho prescrita e a organização do trabalho real. Este esforço envolve o métier, a subversão e a transgressão das regras prescritas para realizar um trabalho bem feito (DEJOURS, 1999, p. 49). Trata-se do reconhecimento do trabalho (e não da pessoa), algo, segundo a Psicodinâmica do Trabalho, essencial para a construção da identidade no trabalho (LANCMAN, 2008, p. 34). Estamos, aqui, diante de um julgamento de beleza (DEJOURS, 1997, p. 54) realizado pelos pares, pelo coletivo ao qual o trabalhador pertence:

Diferentemente da construção da identidade no campo erótico, a construção da identidade no campo social implica não somente a relação com o outro, mas também a referência a um terceiro termo - o real. O reconhecimento da identidade do sujeito no campo social não é direto; diz respeito à relação que o sujeito mantém com o real. Não se trata, portanto, de um julgamento direto do outro sobre o sujeito, que talvez 
dependa do amor, mas de um julgamento sobre a relação do sujeito com o real, que, neste caso, se dá no trabalho. O acesso ao real não é, nunca, imediato: supõe sempre uma instrumentalização, ou seja, um trabalho. O que o sujeito procura fazer reconhecido é o seu fazer e não o seu ser. Portanto, o reconhecimento da identidade no campo social é mediado. Somente depois de ter reconhecida a qualidade de meu trabalho é que posso, em um momento posterior, repatriar esse reconhecimento para o registro da identidade. (DEJOURS, 1999, p. 21)

O que extraímos, afinal, das noções dejourianas de sublimação (DEJOURS; ABDOUCHELI; JAYET, 1994, p. 37), de identidade, de compromisso, de reconhecimento e de alienação é fundamental para compreender o tema, ora proposto, do mundo contemporâneo do trabalho e da saúde mental do trabalhador. Defendemos a tese de que as novas atividades de trabalho, aqui focadas, comprometem a saúde mental porque: dificultam drasticamente a utilização de recursos necessários para a sublimação (DEJOURS; ABDOUCHELI; JAYET, 1994); não satisfazem as necessidades de reconhecimento (DEJOURS, 1999, p. 97-98; DEJOURS, 2006, p. 34); comprometem um compromisso eficaz (do ponto de vista da saúde) entre sofrimento e defesas (DEJOURS, 1996); e dificultam a consolidação da identidade pelo trabalho. A questão da identidade é fundamental, pois:

O trabalho se inscreve então na dinâmica de realização do ego. A identidade constitui uma armadura da saúde mental. Não há crise psicopatológica que não esteja centrada numa crise de identidade. Eis o que confere à relação para com o trabalho sua dimensão propriamente dramática. Não podendo gozar os benefícios do reconhecimento de seu trabalho nem alcançar assim o sentido de sua relação para com o trabalho, o sujeito se vê reconduzido ao seu sofrimento e somente a ele. Sofrimento absurdo, que não gera senão sofrimento, num círculo vicioso e dentro em breve desestruturante, capaz de desestabilizar a identidade e a personalidade e de levar à doença mental. (DEJOURS, 2006, p. 34-35)

A identidade pelo trabalho, no entendimento da saúde mental, é um traço marcante da Psicodinâmica do Trabalho. Para entender saúde e sofrimento no trabalho, temos buscado, em nossos estudos, compreender como o reconhecimento (pelo outro), num julgamento de beleza e utilidade - para utilizar os termos de Dejours (1997, p. 54) - é fundamental para a constituição da identidade.

O trabalho tem, ainda, uma função psíquica: é um dos grandes alicerces de constituição do sujeito e de sua rede de significados. Processos como reconhecimento, gratificação, mobilização, mobilização da inteligência, mais do que relacionados à realização do trabalho, estão ligados à constituição da identidade e da subjetividade. (LANCMAN, 2008, p. 31)

Quando estes processos acima citados encontram-se impedidos ou dificultados, abre-se espaço para o sofrimento e, talvez, posteriormente, para as descompensações psicopatológicas. Isso nos tem permitido compreender a gênese dos danos à estrutura psíquica dos trabalhadores pela organização do trabalho em suas novas facetas no mundo contemporâneo.

\section{Psicodinâmica do Trabalho e a produ- ção de serviços contemporânea: o caso do setor de teleatendimento}

Na produção de serviços da atualidade, pautada pelas modernas tecnologias da informação aplicadas na gestão e no maior controle do trabalho (GALVÃO; SILVA; COCCO, 2003) - num cenário próprio ao que estes autores chamam de "capitalismo cognitivo" - a situação é bem grave do ponto de vista da saúde mental. Quer estejamos falando de um serviço de vendas, cujos resultados e indicadores das vendas de um trabalhador são transformados em símbolos manipulados por um programa de computador; ou de um serviço de ensino, no qual notas, frequências, desempenhos, etc. são controlados por intermédio de um sistema informacional; ou ainda de um serviço de teleatendimento, no qual as tecnologias da informação permitem monitorar e controlar os tempos de atendimento, a qualidade do mesmo, a linguagem, o número de atendimentos realizados por unidade de tempo etc. - percebemos que há algo em comum entre diferentes produções de diferentes tipos de serviços, que impacta, significativamente, em todos eles, a relação saúdetrabalho, segundo a Psicodinâmica do Trabalho: maior controle do trabalho e menor autonomia para a livre elaboração dos modos operatórios e das estratégias de ação. Já é bem conhecida, desde a Psicopatologia do Trabalho até à Psicodinâmica do Trabalho, a sensível relação entre dois termos: funcionamento psíquico e rigidez do controle pela organização do trabalho. Onde se exacerba o segundo termo, restringindo a margem de manobra para as mudanças nas formas de trabalhar, compromete-se o primeiro, como já bem conhecido desde os estudos e as críticas sobre o modo taylorista de organização do trabalho e seus impactos sobre o funcionamento psíquico dos indivíduos (DEJOURS, 1992). Diferentes tipos de serviços, com seus modernos sistemas automatizados de monitoramento e controle do trabalho, têm trilhado este caminho já bem conhecido, de uma retaylorização de cadências, gestos, tempos, movimentos etc. do trabalho.

Além disso, ao contrário da produção de um bem material, cujo produto é palpável e pode ser avaliado em suas qualidades materiais, o produto de um serviço é imaterial e intangível, o que dificulta a sua avaliação enquanto resultado de um trabalho. O produto do trabalho é algo intangível: um serviço. Não é porque se trata de um serviço em que não se pode reconhecer o trabalho. Não é isso. O que se verifica, na prática, é que o reconhecimento pelos pares, e até mesmo pela hierarquia, é difícil (mas não impossível) visto que poucos têm como avaliar e julgar o produto. Lembremos do produto do trabalho de um professor, ou de um psicólogo clínico ou psicanalista, ou ainda do trabalho de um bancário, vendedor, teleatendente etc. A escassez de reconhecimento, conforme já explicamos anteriormente, é nociva do ponto de vista da saúde mental, permitindo compreender as origens do sofrimento e das descom- 
pensações psicopatológicas. A construção da identidade, portanto, encontra-se severamente prejudicada nos novos trabalhos em serviços, como exemplificaremos pelo serviço de teleatendimento. O produto geralmente se torna aparente quando é malsucedido: reclamação, má avaliação de um atendimento por telefone. O trabalhador se vê impedido de livre criação onde predomina a prescrição. Há um conflito irreconciliável entre as exigências de qualidade e as de tempo que afeta o funcionamento psíquico: é preciso atender um cliente com qualidade, mas, ao mesmo tempo, não se pode gastar muito tempo com ele, visto que a quantidade de clientes atendidos é um parâmetro de avaliação.

Conforme observado por nós em nossos mais recentes estudos empíricos, ${ }^{2}$ temos que quem visita uma central de teleatendimento (CT) do mundo contemporâneo e se atem a observar os seus traços concretos acredita estar diante de um trabalho salutar. O ambiente parece agradável. Boa iluminação, chão e mobiliários reluzentes de tão limpos. Moças jovens sempre sorridentes, bem maquiadas e impecavelmente vestidas. Rapazes também jovens, bem humorados, "vestindo a camisa da empresa”, sempre dispostos ao trabalho. Ar-condicionado, muita fala, muita conversa, sorrisos, energia que contagia quem passa por ali, conforme atestam nossas próprias observações empíricas ${ }^{2}$. Mas, sob a ótica da Psicodinâmica do Trabalho, a realidade é outra. Por detrás da fachada concreta do bem-estar aparente, escondem-se o mal-estar e o sofrimento de quem trabalha; é a denominada "normalidade sofrente" (DEJOURS, 2006, p. 36).

As centrais de teleatendimento por nós estudadas recentemente, com seus aspectos de controle rígido do trabalho e prescrição dos modos operatórios, assemelham-se às fábricas tayloristas ${ }^{2}$. A prescrição e o controle, que, nas segundas, incidiam sobre os gestos e os movimentos do corpo físico, nas primeiras, incidem sobre os atos de comunicação (as falas são padronizadas as respostas ao cliente não podem ser escolhidas livremente, mas seguem um protocolo de verbalizações autorizadas, etc.), sobre o comportamento (não falar em tom alto, usar vestimenta padronizada, não mascar chiclete, usar maquiagem, nunca sair do posto de trabalho), sobre a subjetividade (é preciso estar "alegre" o tempo todo, "motivado", de "bom astral" e, principalmente, "vestir a camisa da empresa”...), sobre o espaço (rigidamente delimitado - cada qual ocupando sua posição de atendimento ou PA), sobre os fluxos telefônicos, os atendimentos, as conversas, os tempos de duração dos intercâmbios, o volume e a qualidade de atendimento, as metas a alcançar. Os trabalhadores relatam que se sentem invadidos, controlados, vigiados, observados em todos os instantes, ininterruptamente. Há os supervisores, em cada área, que fazem o controle exacerbado do trabalho funcionar em tempo real.

A rotina de trabalho das centrais de teleatendimento por nós pesquisadas é pautada pela repetitividade, com procedimentos de atendimento padronizados. A tarefa (trabalho prescrito) é pautada por regras formais rígidas e inflexíveis. A hierarquia é muito bem delimitada e explícita. O trabalho é realizado sob diferentes formas de constrangimentos (contraintes), em destaque o constrangimento temporal. Este modelo de organização do trabalho é fonte de sofrimento patogênico, anula as possibilidades de reconhecimento e de identidade no trabalho, inviabiliza os processos de sublimação e gera aumento da carga psíquica por, também, comprometer as descargas das excitações pelas vias psíquica, motora ou psicomotora (comportamental) (DEJOURS; ABDOUCHELI; JAYET, 1994, p. 23). As estratégias coletivas de defesa encontram-se dificultadas pela organização do trabalho. Algumas estratégias individuais de defesa são possíveis, como a autoaceleração das cadências.

A taylorização é a marca essencial do trabalho de teleatendimento. E com ela encontramos todos os problemas já classicamente descritos pela Psicodinâmica do Trabalho para as organizações tayloristas (DEJOURS, 1992; DEJOURS; ABDOUCHELI; JAYET, 1994). Portanto, a nossa contribuição aqui é mostrar como estes problemas afetam os trabalhadores de um serviço relativamente novo no cenário contemporâneo, visto que outras colaborações, neste sentido, se aplicavam às indústrias tayloristas. Como em toda organização do trabalho taylorista, ocorre um bloqueio entre o ego e o outro (alienação), o que inviabiliza as possibilidades de reconhecimento, de intercompreensão e de construção de modos coletivos para lidar com o sofrimento, inclusive estratégias coletivas de defesa.

As gerências das CT's padronizam as condutas de atendimento dos trabalhadores por meio de roteiros ou scripts. O trabalho é controlado em tempo real, mediante o emprego de sistemas de monitoramento das conversas ao telefone. A carga cognitiva é alta (raciocínio, memória, concentração, tomada de decisão em tempo curto) e as exigências afetivas da atividade são elevadas (tolerar frustrações, agressões, mantendo a cortesia, a entonação de voz, a postura cordial nas falas; manter o equilíbrio emocional num cenário de rígida prescrição, controle e invasão da individualidade).

Alguns dos dados obtidos indicam o esgotamento emocional e refletem vivências subjetivas relacionadas ao trabalho, como inutilidade, insegurança e frustração. Não são detectados sinais de vivências de gratificação com o trabalho nem de realização com ele. Não há liberdade para pensar sobre o trabalho nem para falar sobre ele. Principalmente do ponto de vista da Psicodinâmica do Trabalho, não existe o reconhecimento (nem pelos pares, nem pela hierarquia), o que é essencial para tolerar o sofrimento e alcançar alguma satisfação com o trabalho. A falta de reconhecimento gera as vivências de indignação e desvalorização, comprometendo a identidade no trabalho, em conformidade com a Psicodinâmica do Trabalho.

${ }^{2}$ Dados ainda não publicados. 
A relação com os clientes é outra fonte de sofrimento. A maioria das ligações recebidas provém da necessidade de fazer reclamações, reivindicações, de solicitar explicações, de buscar razões para problemas e falhas no serviço. Nestes contextos, impera a agressividade por parte do cliente, que considera o atendente como sendo a própria empresa. Os constrangimentos, nestes casos, são fortes e diversificados. Não se pode destratar um cliente, revidar as agressões nem interromper a ligação. O temperamento e o humor do cliente são fontes de variabilidade e de imprevisibilidade do sistema de teleatendimento, o que aumenta a complexidade do trabalho e requer, dos trabalhadores, estratégias e compromissos cognitivos (AMALBERTI, 1996) sofisticados para lidar com esta complexidade.

O trabalho não permite, neste caso, ao sujeito realizar suas aspirações e seus desejos, interpondo-se como obstáculo ao livre exercício de si mesmo na atividade. Isso torna o trabalho agressivo ao aparelho psíquico.

Como em todo trabalho taylorizado, as tarefas são individualizadas, compromete-se a existência de uma partilha intersubjetiva no interior do coletivo de trabalho. Não há condições de possibilidade para uma deliberação coletiva, na qual os problemas seriam discutidos pelo grupo, compartilhados e as soluções seriam encontradas em comum acordo. Este espaço de deliberação coletiva eficiente, de discussão, em que ocorre a intercompreensão, orientada para o entendimento (DEJOURS, 1997, p. 71), é fundamental para que ocorra a psicodinâmica do reconhecimento e para que haja o fortalecimento dos processos subjetivos e intersubjetivos de enfrentamento do sofrimento no trabalho.

Não havendo a comunhão na intersubjetividade, na comunicação, no diálogo, estão vedadas as possibilidades de amenizar e de enfrentar o sofrimento de forma coletiva, com o anteparo do grupo, com o seu apoio para a criação de mecanismos e estratégias coletivas de defesa. O sofrimento é, assim, vivenciado na solidão, no interior do mundo singular que cada um mantém em sua subjetividade.

A possibilidade de simbolizar pela linguagem, ao menos em parte, aquilo que se faz no real do trabalho está impedida. A retribuição moral-simbólica que o trabalhador necessita receber do coletivo está seriamente comprometida, assim como as trocas subjetivas e a própria manutenção de um plano intersubjetivo. A construção identitária, na interação entre o que é da ordem singular (subjetiva) e o que é da ordem coletiva (intersubjetiva), torna-se precária, visto que ela depende destas trocas e do próprio universo intersubjetivo tecido na atividade de trabalho. O trabalho se torna fonte de alienação e sofrimento ao falhar em sua função de operador do simbólico. A coesão de um coletivo se dá pela experiência recíproca da linguagem, num agir comunicativo, criador de um espaço comum de discussão. Quando este espaço falha em sua função, falha a ética da discussão, falha também o esforço de confrontar a rigidez das prescrições, pois não há poder engendrado comunicativamente, tecido coletivamente, a articular a intersubjetividade. O sujeito não pode falar de modo criativo, mas deve reproduzir a fala do outro. A impessoalidade assume o comando nas falas. E sem uma mobilização da dinâmica intersubjetiva, como nos é afirmado abaixo, não há solução terapêutica:

\begin{abstract}
A solução "terapêutica" consiste aqui em estimular a dinâmica intersubjetiva de transformação da organização do trabalho. É a contribuição para este processo de transformação que permite aos sujeitos conjurar o sofrimento. Conjurar, transformar em sentido, em inteligibilidade e em ação não significa que se anula, que se apaga o sofrimento, pode-se apenas transformá-lo em sentido e eventualmente em prazer: o prazer da reapropriação do vivido pela ação. (DEJOURS; ABDOUCHELI; JAYET, 1994, p. 86)
\end{abstract}

O impedimento da palavra autêntica assevera a desconexão entre pensamento e execução e, deste modo, realizar a tarefa é perder a realidade; a objetivação é a perda do objeto. O trabalhador torna-se desapropriado de seu trabalho; seus atos (de comunicação) se tornam estranhos a si próprio. O rompimento com este mal patogênico deveria se dar pelo recurso à própria palavra, num espaço coletivo de discussão e deliberação. Como tal espaço é inexistente, surge a alienação. Há uma descontinuação do sujeito social face ao sucateamento do símbolo e à exclusão da linguagem autêntica. O trabalho jamais toma a palavra nestes casos, não podendo, então, ser ressignificado no coletivo, nem promover a religação entre pensamento e execução. Jamais se verifica, assim, o fenômeno de uma consciência compartilhada como mobilização psíquica do todo e voltada para a socialização e construção de um espaço intersubjetivo.

\section{Psicodinâmica do Trabalho na indústria automatizada contemporânea}

Partimos, aqui, do pressuposto de uma interdependência entre os componentes da carga de trabalho, sendo que, do ponto de vista econômico da carga psíquica em Psicodinâmica do Trabalho (DEJOURS; ABDOUCHELI; JAYET, 1994, p. 23), ela - a carga psíquica - funciona como um operador dos demais componentes (físicos e cognitivos).

A atividade cognitiva é essencialmente tácita. Ou seja, os manejos, as artimanhas, as habilidades e os compromissos são cognitivos, implícitos, e são necessários para que o trabalhador realize bem o seu trabalho. Estes elementos invisíveis da inteligência prática, no entanto, geram medo, angústia e ansiedade frente ao risco de insucesso (incidentes, acidentes, anomalias no processo). Isso ocorre porque esta atividade de regulação cognitiva é implícita, tácita, não é reconhecida, não é legitimada e opera na clandestinidade. Ela envolve o "quebra-galho" - tricherie, em francês (DEJOURS; ABDOUCHELI; JAYET, 1994, p. 93-107) - a transgressão de regras e normas para o sucesso do trabalho (DEJOURS, 1999, p. 49-66) e deixa o trabalhador exposto ao risco do fracasso, o que acarretaria punições e até demissão. 
A modernização dos sistemas de produção, nos últimos 15 anos, pela introdução dos sistemas automatizados de controle de processo, aparece como uma das condições de sobrevivência das IPC's (Indústrias de Processo Contínuo). As indústrias têm, então, buscado utilizar sistemas de controle com desempenho cada vez melhor, o que impacta significativamente no trabalho dos operadores (THIBAULT, 2002).

A atividade de controle dos processos contínuos contemporâneos é essencialmente cognitiva. E o que complexifica esta atividade, além da necessidade de tomar decisões em tempo real e de ter que lidar com programas de computador sofisticados, cujo modelo de funcionamento escapa aos operadores, é principalmente ter de lidar com as denominadas situações dinâmicas, que, associadas ao aumento exacerbado da carga cognitiva, impõem a necessidade de uso dos "quebragalhos" e das transgressões de normas para que os objetivos e resultados sejam alcançados.

A atividade cognitiva é complexa e a carga cognitiva de trabalho é excessivamente alta por várias razões. As situações dinâmicas se caracterizam pelas possibilidades limitadas de controle por parte dos operadores - ou “controle parcial”, conforme Hoc (2004, p. 517), e pela incerteza. Isso tende a aumentar a complexidade da atividade de trabalho e a elevar a carga cognitiva.

São necessárias, a todo momento, regulações e adaptações para a gestão das situações dinâmicas. A supervisão e o controle eficaz dos modernos processos produtivos contemporâneos (complexos) - pautados pelas situações dinâmicas - dentro dos parâmetros de normalidade, não resultam do sistema automatizado e de suas regras, tampouco das regras explícitas do trabalho prescrito aos operadores. O ajuste fino (articulando as demandas da situação dinâmica e a ação do operador para arcar com tal situação) e as regulações, necessárias à manutenção do sistema em conformidade com os objetivos predefinidos, resultam da intensa atividade cognitiva dos operadores com todas as transgressões encontradas no trabalho real.

São estes componentes de uma intensa atividade cognitiva (e subjetiva) que operam, no real do trabalho, de modo a permitir que o homem (operador) funcione como um agente de confiabilidade na gestão, eficiente e eficaz, das situações dinâmicas em sistemas complexos.

A ação dos operadores excede o fazer no trabalho. Em outras palavras, a ação comporta articulações e compromissos no trabalho real que não podem ser explicados apenas pelo comportamento (HUBAULT, 2004). Temos, no presente caso, os compromissos cognitivos (AMALBERTI, 1996) que comportam regulações e estratégias para lidar com diferentes situações. É, de fato, a cognição dos operadores que efetivamente garante a confiabilidade da gestão de situações dinâmicas, do controle de processos de produção, pautados pela complexidade, pela imprevisibilidade e pela variabilidade.

Os riscos associados aos sistemas contínuos de produção (HOC, 2004), como, por exemplo, os riscos de se provocar uma pane, uma explosão ou um acidente pelo acionamento de um comando computadorizado incorreto num momento de decisão, a carga cognitiva elevada e a ausência de reconhecimento colocam os sujeitos à deriva no sofrimento causado pelo medo do fracasso e da exclusão. Temos aqui, também, todos os problemas já descritos no que tange às possibilidades de consolidação da identidade pelo trabalho: o elo do sujeito com o real do trabalho não é visível ao olhar do outro. A porta para os problemas de ordem psíquica e até para as descompensações mentais está, portanto, escancarada no moderno trabalho com os sistemas automatizados.

A planificação da ação, necessária em tempo real, gera a ansiedade por poder conduzir a uma degradação da performance, requerendo artimanhas e saberes que não são reconhecidos pela organização prescrita do trabalho. Trabalha-se com medo, ansioso, angustiado, pois, jamais se sabe qual será, ao certo, o resultado das ações que, indubitavelmente, poderão ser punidas quando fracassarem por não serem legitimadas pelas normas prescritas. Estar constantemente fora das normas, por necessidade de trabalhar bem, é algo patogênico e pode levar à degradação da saúde mental. O risco do fracasso faz parte da atividade de controle do processo aliado à ausência de reconhecimento e ao isolamento ou clausura cognitiva na qual o trabalhador está inserido, solitário.

O motor do sofrimento nos sofisticados sistemas de controle de produção dos modernos cenários produtivos é a incerteza. Conforme anteriormente explicado, estes sistemas se pautam pelas chamadas situações dinâmicas, que os tornam complexos e traz aos trabalhadores um frente a frente com a incerteza, com o desconhecido. Isso gera o medo, a ansiedade e a angústia de não conseguir resolver os problemas do processo da forma esperada pelas gerências.

Além dos “males da incerteza”, encontramos, também aqui, a quase impossibilidade das estratégias coletivas de defesa, visto que cada operador trabalha sozinho em seu turno, não tem como verbalizar suas experiências predominantemente subjetivas ou suas estratégias cognitivas e, principalmente, os "quebra-galhos” não são compartilhados pelos trabalhadores. "Você faz isso assim, usa este macete, quebra o galho assim ou assado para resolver o problema?" A esta questão, formulada por um colega de trabalho ao outro, ao seu par, a resposta é: "Não, eu nunca faço isso. Eu somente faço o que mandam as normas”. Ora, entre os próprios colegas não há reconhecimento, não há comunhão de algo que todos fazem e que não reconhecem perante os próprios pares.

O elo do sujeito com o real permanece clandestino, sem visibilidade ao outro e sem reconhecimento por parte do outro. Isso é patogênico à saúde psíquica, conforme já explicado. O que se faz no trabalho real não se torna visível. Ninguém fala. Ninguém verbaliza. O coletivo não discute, não dialoga. Não se cria espaço para discussão, para a deliberação coletiva, para a partilha de vivências e experiências. Não há trocas simbólicas entre os próprios pares. Entre os colegas, predominam a dissimulação, a ocultação de experiências que deve- 
riam ser compartilhadas e reconhecidas por eles entre os próprios pares. Reina o silêncio, a reserva. Silêncio deveras nocivo aos próprios trabalhadores. O coletivo perde o seu sentido, se resumindo a um grupo de individualidades isoladas, solitárias em seu mundo. Assim, as estratégias coletivas de defesa tornam-se difíceis. Não há partilha, no coletivo, de um mundo subjetivo puramente vivenciado de forma individual. Sujeito e tecnologia constroem um mundo, um amálgama entre si, que o isola e o torna solitário em relação ao restante do universo social da empresa. Insegurança, incerteza, desconfiança predominam no cenário do trabalho pautado pelas tecnologias de ponta. Escamotear, esconder-se, omitir-se, negar o que se faz são as palavras de ordem entre os trabalhadores das situações dinâmicas e complexas.

Um grave problema nestes modernos sistemas de controle é o do reconhecimento, como também já fora anteriormente explicado para o setor de serviço de teleatendimento. Por se tratar de um termo essencial para a Psicodinâmica do Trabalho, vamos nos deter e aprofundar mais um pouco sobre como o problema do reconhecimento afeta o trabalho de controle de processo contínuo de produção.

Conforme já explicado neste texto, Dejours (2006, p. 34) usa o termo "psicodinâmica do reconhecimento” para designar o quão salutar, para a vida psíquica e para a identidade no trabalho, é o julgamento de beleza que o coletivo e os pares fazem do esforço do sujeito para suprir as carências da organização prescrita do trabalho. Esforço que envolve o métier, a inteligência da prática, a inteligência astuciosa, as habilidades tácitas. No entanto, o sujeito, diante das telas do seu sistema de controle, está só. Suas ações, sua perícia, seu métier, ficam enclausurados em sua interação cognitiva com o sistema, não ganhando visibilidade perante os colegas e perante a hierarquia. Quando tudo funciona dentro da normalidade, ninguém é capaz de reconhecer que, por trás desta aparente tranquilidade, foram travadas lutas incansáveis com os dispositivos técnicos, com sensores, alarmes e principalmente com as regras do sistema que não ganham sentido na atividade. Tudo fica escamoteado em perigoso e maléfico silêncio. A normalidade do funcionamento destes sistemas de produção esconde um esforço incomensurável do operador para manter o processo sob controle. Isso é invisível, visto que as ações não se resumem aos comportamentos; o agir no trabalho de controle e supervisão de modernos processos excede o fazer. É na atividade cognitiva, muda, tácita, invisível e, às vezes, intangível, que se passa uma verdadeira jornada de muito esforço (a carga cognitiva da atividade, conforme já explicado, é elevada principalmente em função das situações dinâmicas), de muita luta contra as oscilações do processo e, principalmente, luta contra o medo de fracassar e contra a angústia diante da incerteza. Luta na solidão, na falta de amparo do próprio coletivo de pertença.

Uma outra fonte do medo e da ansiedade dos operadores de processo contínuo é o que ora denominaremos de "encruzilhada" entre a organização prescrita do trabalho e o real do trabalho. Utilizaremos, aqui, a noção de Dejours (1997, p. 40-43) para real do trabalho, ou seja, aquela parte da realidade que escapa ante as tentativas de simbolização, que recua, que não se mostra, que permanece obscura, sem inteligibilidade. O operador vive numa encruzilhada. Se seguir à risca o que determina a organização prescrita do trabalho, dificilmente conseguirá alcançar os resultados e os objetivos definidos pela própria organização. O que é necessário fazer, principalmente cognitivamente, para manter a produção dentro dos parâmetros esperados de normalidade não pode ser prescrito, porque este "fazer" envolve o agir que excede o que dizem as normas. $\mathrm{O}$ agir do operador situa-se no real do trabalho: é algo tácito, que envolve as habilidades tácitas, a inteligência da prática, a inteligência astuciosa, o "jeitinho", a artimanha (DEJOURS, 1997, p. 43-48) e o "quebra-galho”.

Com efeito, parece que em todos os lugares do "Ser-
viço Trabalhos", as pessoas são obrigadas a "quebrar-
galhos" para enfrentar as consígneas, os gammes ou
os regulamentos, para bem desempenhar o trabalho
nos prazos previstos. Esta prática do quebra-galho,
se ela é inevitável, nas atuais condições de trabalho,
é bem útil. Na medida em que quebrar o galho é ofi-
cialmente proibido, o silêncio, o segredo dos agen-
tes, que temem ser surpreendidos, denunciados ou
punidos é, talvez, em certos casos, bem útil à chefia,
pois, se ela soubesse de tudo a cada instante, seria
obrigada, a bem da ordem, a reduzir consideravel-
mente o ritmo da execução do trabalho. (DEJOURS;
ABDOUCHELI; JAYET, 1994, p. 93)

Agir de forma eficaz, porém, com medo de ser surpreendido, denunciado, punido. Eis a sina dos operadores dos sistemas de controle de processos contínuos no mundo contemporâneo. A ação se torna clandestina e transgressora. Clandestinidade e transgressões eficazes, úteis, mas que oferecem riscos de punição, de demissão. Isto é fonte de medo, ansiedade e angústia.

\begin{abstract}
Em outros termos, o paradoxo da fraude é a dificuldade que decorre de fazer reconhecer seu valor, sua experiência, sua competência e sua capacidade de iniciativa. Se quebro-galhos, corro o risco de ser punido; se não o faço, corro o risco de ser acusado de falta de iniciativa. É exatamente esta injunção paradoxal que é: causa de sofrimento; causa de mal-entendidos; causa de sonegação e má circulação de informações; causa de fechamento sobre si mesmo e de desconfiança individual; causa de sentimento de injustiça. (DEJOURS; ABDOUCHELI; JAYET, 1994, p. 102)
\end{abstract}

Em conformidade com os autores acima, detectamos que quebrar galhos não é algo fácil. Implica em assumir severos riscos: 1) riscos técnicos (riscos de danos às instalações, aos equipamentos e riscos de segurança das pessoas); 2) riscos pessoais (ser punido e até ser demitido; ser recriminado pelos próprios colegas); 3) riscos de fracasso (falhar, não obter os resultados estipulados); 4) riscos subjetivos (não suportar as pressões, a angústia, a ansiedade, o medo e, em alguns casos, a culpa).

O quebra-galho suscita a prática do segredo e situa-se num plano fundamental para a compreensão do sofrimento. O sujeito, que deve manter suas ações em segredo, não pode se abrir. Não pode falar. Os males causados pelo 
impedimento do recurso à fala e das trocas simbólicas já foram tratados anteriormente neste texto. Aqui não é diferente. Além disso, o sujeito está clivado por uma encruzilhada ou pelo paradoxo da prática. É obrigado, pelas demandas da situação, a se valer dos quebra-galhos. Mas toda inventividade, criatividade e inteligência aí mobilizadas não auferem nenhum reconhecimento, o que, também, conforme já explicado, torna-se nocivo para a identidade no trabalho, para o funcionamento do aparelho psíquico e, finalmente, pode levar a algumas formas de alienação já bem descritas por Dejours como a alienação mental e a alienação social. No presente caso, encontramos com facilidade a vertente da alienação social na indústria de processo contínuo, principalmente no problema do "quebra-galho" não reconhecido:

A segunda forma de loucura é a alienação social. Dessa vez, o sujeito conserva uma relação legítima com o Real, mas essa relação não é compreendida ou reconhecida pelo outro. (...) Essa situação não apresenta nada de excepcional, sendo muito freqüente no mundo do trabalho, onde constitui o essencial do que é o próprio objeto do sofrimento no trabalho e da psicopatologia do trabalho. Se esse não-reconhecimento for durável, o sujeito correrá o risco, como no caso da alienação mental, de ficar louco. (DEJOURS, 1999, p. 22-23)

Eis o risco do trabalho contemporâneo diante dos modernos sistemas automatizados nas indústrias de processo contínuo: o não reconhecimento, o isolamento no silêncio, na dissimulação, na negação da própria ação.

Se a ação de quebrar galho é necessária para lidar com as situações dinâmicas e com a complexidade dos modernos sistemas produtivos, ela é também ilegal, fraudulenta e transgressora, não sendo sequer reconhecida. Trabalhar bem é incorrer na ilegalidade, na fraude, na transgressão do quebra-galho:

estes quebra-galhos necessários são a forma que tomam a inventividade, a imaginação e a criatividade dos agentes. O quebra-galho tal qual é praticado atualmente é uma condição essencial para o funcionamento, mas também para a melhoria das condições e da organização do trabalho. É a partir de e graças a ele que novas competências podem ser experimentadas e, em seguida, capitalizadas nas ordens de serviço e nos gammes. (DEJOURS; ABDOUCHELI; JAYET, 1994, p. 100)

\section{Considerações finais}

A Psicodinâmica do Trabalho trouxe consideráveis contribuições teórico-metodológicas para o campo da Psicologia do Trabalho e, em especial, para a área da Saúde Mental e Trabalho. A abordagem dejouriana veio suprir uma lacuna histórica nos estudos sobre os impactos do trabalho sobre a vida mental ao reforçar a centralidade do trabalho na compreensão não apenas da doença, mas também da saúde e do prazer. A normalidade, dantes pautada pelo senso comum, adquiriu o status de objeto de investigação científica, trazendo à tona a questão do sofrimento e, principalmente, o compromisso entre sofrimento e defesa.

Com as contribuições da tradição compreensiva das ciências hermenêuticas, a Psicodinâmica do Trabalho auferiu o poder de adentrar um espaço antes desconhecido da psicologia do trabalho: o das vivências individuais, quer elas envolvam o sofrimento ou o prazer no trabalho. O nexo entre o coletivo e o individual pode ser delineado, como atesta C. Dejours, ao afirmar que, embora o sofrimento esteja alicerçado nas bases coletivas da organização do trabalho (categoria que incide sobre um coletivo), ele é, entretanto, experimentado, vivenciado individualmente. As patologias que partem de um modo específico de organização do trabalho e se manifestam em determinados indivíduos também podem ser compreendidas pelo itinerário teórico e metodológico da Psicodinâmica do Trabalho.

No mundo do trabalho contemporâneo, as alegrias são públicas - como atestam mecanismos de distorção comunicacional das empresas modernas (DEJOURS, 2006, p. 61-72): abundam folhetins, panfletos e demais instrumentos de divulgação que mostram ambientes limpos, bem iluminados, trabalhadores sorridentes e declarações de satisfação e de realização com o trabalho. No entanto, o sofrimento é velado, oculto. A empreitada de compreendê-lo, por sob a fachada reluzente e aprazível ostentada pelas organizações, é uma das maiores contribuições científicas da Psicodinâmica do Trabalho para o debate: "o mundo contemporâneo do trabalho e a saúde mental do trabalhador”.

\section{Referências}

AMALBERTI, R. La conduite de systèmes à risques. Paris: Presses Universitaires de France, 1996.

DEJOURS, C. A loucura do trabalho: estudo de psicopatologia do trabalho. São Paulo: Cortez, 1992.

. Psychologie clinique du travail et tradition compréhensive. In: CLOT, Y. (Org). Les histoires de la psychologie du travail: approche pluri-disciplinaire. Paris: Octares Editions, 1996. p. 195-219.

. O fator humano. Rio de Janeiro: FGV, 1997.
. Conferências brasileiras: identidade, reconhecimento e transgressão no trabalho. São Paulo: Fundap; EAESP/FGV, 1999.

. A banalização da injustiça social. Rio de

Janeiro: FGV, 2006.

DEJOURS, C.; ABDOUCHELI, E.; JAYET, C. Psicodinâmica do trabalho: contribuições da escola dejouriana à análise da relação prazer, sofrimento e trabalho. São Paulo: Atlas, 1994. 
GALVÃO, A. P.; SILVA, G.; COCCO, G. Capitalismo cognitivo: trabalho, redes e inovação. Rio de Janeiro: DP\&A, 2003.

HOC, J. M. La gestion de situation dynamique. In: FALZON, P. (Org.). Ergonomie. Paris: Presses Universitaires de France, 2004. p. 517-530.

HUBAULT, F. Do que a ergonomia pode fazer análise? In: DANIELLOU, F. (Org.). A ergonomia em busca de seus princípios: debates epistemológicos. São Paulo: Edgard Blücher, 2004. p. 105-140.

LANCMAN, S. O mundo do trabalho e a psicodinâmica do trabalho. In: LANCMAN, S.; SZNELWAR, L. I. (Org.). Christophe Dejours: da psicopatologia à psicodinâmica do trabalho. Rio de Janeiro: Fiocruz, 2008. p. 25-36.

LANCMAN, S.; UCHIDA, S. Trabalho e subjetividade: o olhar da Psicodinâmica do Trabalho. Cadernos de Psicologia Social do Trabalho, São Paulo, v. 6, p. 79-90, 2003.

MORAES NETO, B. R. Marx, Taylor e Ford: as forças produtivas em discussão. São Paulo: Brasiliense, 1989.

THIBAULT, J. F. Contribuição da ergonomia em projetos de concepção e implantação de SDCD. In: DUARTE, F. (Org.). Ergonomia e projeto na indústria de processo contínuo. Rio de Janeiro: Lucerna, 2002. p. $173-186$. 